\title{
HispanismeS
}

Revue de la Société des Hispanistes Français

\section{De la señalización de las fosas comunes a su representación en las calles.}

Monumentos, marchas y grafitis frente a la Memoria Histórica

De la signalisation des fosses communes à leur représentation dans les rues

From the marking of mass graves to their representation in the streets

\section{Daniel Palacios González}

\section{(2) OpenEdition}

\section{Journals}

Edición electrónica

URL: https://journals.openedition.org/hispanismes/327

DOI: 10.4000/hispanismes.327

ISSN: 2270-0765

Editor

Société des Hispanistes Français

Referencia electrónica

Daniel Palacios González, «De la señalización de las fosas comunes a su representación en las calles.», Hispanismes [En línea], 14 | 2019, Publicado el 01 octubre 2019, consultado el 31 agosto 2021. URL: http://journals.openedition.org/hispanismes/327 ; DOI: https://doi.org/10.4000/ hispanismes.327

Este documento fue generado automáticamente el 31 agosto 2021.

\section{cc) (†) $\odot$}

Les contenus de cette revue sont mis à disposition selon les termes de la Licence Creative Commons Attribution - Pas d'Utilisation Commerciale - Pas de Modification 4.0 International. 


\title{
De la señalización de las fosas comunes a su representación en las calles.
}

\author{
Monumentos, marchas y grafitis frente a la Memoria Histórica \\ De la signalisation des fosses communes à leur représentation dans les rues \\ From the marking of mass graves to their representation in the streets
}

Daniel Palacios González

\section{Introducción}

1 Cuando recibí la convocatoria de la "Journée d'Études STREET ART. Territoires physiques, virtuels et interactions" celebrada en 2019 en la Universidad de Rennes 2, la imagen que la acompañaba era un trabajo de Alto de su serie sobre fosas comunes. Estas imágenes se hicieron bastante populares en redes sociales y aplicaciones de mensajería instantánea hace unos años: grafitis que representaban restos esqueléticos fragmentados y amontonados, a los que se añadía un pie indicando Fosa y un número. Los grafitis de Alto tienen una ejecución que a nivel técnico no puede ser discutida. De alguna manera llaman la atención del espectador no habituado a observar una violencia no ficcional como es la de las fosas comunes, o al menos una representación de la misma. Podrían también haberse popularizado por tratarse de una técnica que no está demasiado relacionada con los grupos sociales vinculados a lo que en las últimas décadas se ha denominado movimiento por la recuperación de la Memoria Histórica ${ }^{1}$. Sin embargo, una segunda aproximación crítica a estas imágenes puede ser especialmente reveladora. Quizás no para sacar conclusiones rotundas, pero sí para revelar ciertas paradojas y cambios de paradigmas en las últimas décadas, y de qué manera esa situación ha afectado a la producción de cultura visual en relación a la guerra de 1936 y a la dictadura posterior en el Estado Español. 
2 Mi campo de investigación no es el arte urbano en sí, sino las prácticas monumentales sobre fosas comunes desde $1936^{2}$. Una investigación que a su vez se enmarca en un proyecto más amplio, desde el cual se observan los procesos de exhumación en perspectiva transnacional y comparada ${ }^{3}$. No obstante, la convergencia del grafiti con los monumentos, panteones y rituales de homenaje y reivindicación que abordo desde mi proyecto pasa por referir semánticamente a la fosa misma en todos los casos. De esta manera, pese a tratarse de un referente en común el grafiti es abordado de manera muy dispar. Aparentemente la diferencia pudiera vincularse rápidamente a la técnica, dado que no es lo mismo construir una escultura o ajardinar un recinto que pintar un muro en una zona urbana en desuso. Pero ésta podría deberse por el contrario al cambio de paradigmas en los discursos en relación a las fosas y que son los que han llegado al productor de imágenes no vinculado directamente a la fosa en sí, sino a las mediaciones mediáticas respecto a la misma. Tanto es así que con el presente texto lo que voy a tratar no es tanto de dar un contexto a estas imágenes de fosas comunes que nos pueden llegar, sino interrogarlas y cuestionarlas con el objetivo de plantear la deriva iconográfica y social que ha tenido lugar en el paso de su señalización a su representación en las calles.

3 Aunque los planteamientos aquí propuestos solo representan una pequeña parte de una investigación mucho más amplia, urge señalar como a nivel metodológico, me muevo entre la historia del arte y la etnografía. Los lindes entre disciplinas son precisamente un objetivo a derribar y poco sentido tienen para las tendencias actuales de los estudios de la memoria en la cultura ${ }^{4}$, donde partiendo de Maurice Halbwachs y su concepto de memoria colectiva ${ }^{5}$, Aleida Assmann ha popularizado el plantear las memorias culturales como aquellas materializaciones conscientes de esa memoria colectiva ${ }^{6}$. Precisamente ello me ha permitido abordar con libertad objetos de estudio heterogéneos y no hacer planteamientos deterministas en base a la proyección de un imaginario teórico sobre las imágenes sino cuestionarlas, desde la experiencia empírica al participar de manera consciente de la propia realidad en la que se inscriben. Cuestionarlas y preguntarlas, entendiendo que la imagen, desde un punto de vista warburgiano no es sino "el resultado de movimientos que provisionalmente han sedimentado o cristalizado en ella. Estos movimientos la atraviesan de parte a parte y cada uno de ellos tiene una trayectoria -histórica, antropológica, psicológica- que viene de lejos y que continúa más allá de ella. Tales movimientos nos obligan a pensar la imagen como un momento energético o dinámico, por más específica que sea su estructura"7. Sean por tanto grafitis, marchas o monumentos... pido observarlos así, más allá de los medios técnicos utilizados, como materialización de los debates asociados al concepto de Memoria Histórica, en torno a la justicia y la representación.

\section{Violencia y ostracismo urbano de larga duración}

4 En la centralidad del espacio urbano en el Estado Español, la ausencia generalizada de monumentos dedicados a personalidades o sucesos vinculados a la historia de la Segunda República o a las personas asesinadas durante la Guerra y la Dictadura contrasta con la presencia en todo el territorio de estos monumentos en los cementerios. Son estos los espacios que se han convertido en uno de los lugares con mayor carga simbólica por ser los contenedores generalmente, bien de las fosas comunes, bien de los panteones que alojan los cuerpos exhumados de las mismas. A 
pesar de que la Guerra y la Dictadura han sido largamente estudiadas, urge puntualizar antes de tratar la representación de las fosas en varios aspectos que han condicionado de manera esencial la ubicación de las mismas y su relación con la centralidad del espacio urbano, así como con sus espacios privilegiados de representación simbólica.

En 1936 se produce una sublevación militar, con apoyo de grupos armados fascistas, católicos, y monárquicos, y que gozará del amplio apoyo extranjero, principalmente de Italia, Alemania así como de los Regulares de Marruecos ${ }^{8}$. Pese a su imposición parcial en el territorio, en las zonas donde tiene éxito comienza a desarrollar un aparato represivo cuyo objetivo es la eliminación física de su oposición y potencial oposición. Los sublevados, amparados por el Bando de Estado de Guerra del 18 de julio de 1936, emitido por Francisco Franco desde Santa Cruz de Tenerife, inician el asesinato en masa de decenas de miles de personas 9 . Algo que continuará con el avance del ejército y con el establecimiento en todo el territorio del nuevo Estado Español. Francisco Espinosa señala como en el primer momento, ante la ausencia de unas estructuras estatales claramente definidas, se producen generalmente enterramientos irregulares de las personas asesinadas en fosas comunes, una práctica que progresivamente se abandonaría por la creación de grandes fosas comunes para enterrar de manera organizada a los asesinados como consecuencia de los procedimientos judiciales militares sublevados ${ }^{10}$. Las cifras de esta represión oscilan entre los 100.000 según Santos Julia ${ }^{11}$ y Julián Casanova ${ }^{12}$ y los 130.000 según Francisco Espinosa ${ }^{13}$ o Paul Preston $^{14}$, y podrían superar los 150.000 si todos los archivos fuesen accesibles y se desarrollasen estudios en profundidad en todas las regiones ${ }^{15}$. Estos paisajes del terror, según los define Francisco Ferrándiz ${ }^{16}$, tendrían sin embargo un nexo común. Se encuentran en el exterior de las ciudades : bien en el campo (cunetas, simas, campos...) bien en los cementerios, condenados al exterior siguiendo los criterios científicos higienistas del siglo XIX ${ }^{17}$.

6 No obstante, la particularidad que ha llevado estos espacios periféricos a ser los ejes de la memoria en España, en lugar de los centros de las ciudades (donde podrían haberse erguido monumentos y espacios memoriales) pasa por el consenso político establecido en torno a la muerte de Francisco Franco en 1975. Ante la posibilidad de una ruptura radical con el régimen, se hizo necesaria una reformulación del mismo a través del pacto con algunas fuerzas progresistas, como el Partido Socialista Obrero Español y el Partido Comunista de España, bajo el paraguas de la instauración de una nueva monarquía parlamentaria pluripartidista. Un consenso que no se produce en un marco de estabilidad y paz, sino por el contrario, de represión en las calles y de violencia selectiva contra agentes políticos, de manera que Alfredo Grimaldos señala como cada crimen suponía la cesión por parte de los grupos de izquierda en algún asunto ${ }^{18}$. Pero más allá de las implicancias políticas y económicas, lo fundamental es que este proceso fue acompañado de un pacto de silencio a nivel de las grandes instituciones y medios en lo que a los crímenes cometidos durante la Guerra y la Dictadura se refiere. Se evitó referenciar la represión y los crímenes de la Dictadura, abogando por el olvido en favor del consenso ${ }^{19}$. Así, como señala Paloma Aguilar, el régimen se benefició de la extrema gentileza de una sociedad traumatizada y llena de víctimas a las que no se les concedió reconocimiento, justicia ni reparación ${ }^{20}$.

7 En lo que al espacio público se refiere, esto se tradujo en la ausencia de un programa monumental que hiciera frente a la construcción de una nueva memoria colectiva. También en que la mayor parte del programa monumental de la Dictadura siguiese 
ocupando espacios destacados de la ciudad. Los monumentos a los Caídos por Dios y por España erguidos tras la guerra siguieron ubicados en las plazas de cientos de pueblos en todo el Estado. Cuando estos fueron construidos "En ellos latía una intención política de afirmación del nuevo régimen, un régimen que, en función de su exclusiva idea de lo que era España, dejaba fuera del impulso conmemorativo a esos otros españoles derrotados y humillados de la anti-España" señala Zira Box ${ }^{21}$, una idea que prevaleció al no desarticular su presencia y no contradecirla con un nuevo discurso, por la fidelidad al régimen presente en muchos de los gestores políticos tras la Transición ${ }^{22}$. En contraste, para 1992 el gobierno de Felipe González apostó por la reivindicación del pasado colonial de España en la conmemoración del denominado "V Centenario del Descubrimiento de América”, por la cual Cristóbal Colón goza de un espacio privilegiado en las plazas de Sevilla ${ }^{23}$. El Museo de América es reinaugurado reciclando el proyecto museístico de la Dictadura, que precisamente se integra con el Arco de la Victoria y el programa monumental fascista elaborado para el entorno de Moncloa en Madrid, por donde entró el ejército sublevado en la ciudad ${ }^{24}$. A ello se sumó una apuesta por la escultura en el espacio público vacía de sentido, que en el marco del gran desarrollo urbanístico de las décadas de 1980 y 1990 se materializó en la cultura de la rotonda, elemento vial que se aprovecha para la instalación de obras plásticas heterogéneas pero estandarizadas en su falta de coherencia con el entorno y la desconexión absoluta con la historia del lugar donde se emplazaban ${ }^{25}$.

\section{Volver a las fosas y conectarlas a la ciudad}

8 Frente a esta situación, ya en los años setenta, los primeros monumentos comienzan a ser construidos, cientos de ellos en todo el estado. Bien sobre las propias fosas comunes, cuando estas se ubicaban en los cementerios, bien como panteones en los cementerios tras la exhumación -muchas veces clandestina- de los cuerpos ${ }^{26}$. Monolitos, jardines, esculturas, placas y panteones que explicitan que allí se encuentran los cuerpos de personas asesinadas, permiten significarlas políticamente haciendo referencia a que "Murieron por la Libertad" o que fueron "Asesinadas". La heterogeneidad es absoluta, muchas veces reproducen las estructuras de los panteones familiares, pero en otras se apuesta por formular una nueva identidad monumental basada en esculturas abstractas, obeliscos o monolitos. Todas ellas, no obstante, comparten la función de señalizar un patrimonio incómodo : la fosa común heredada. Sin embargo, estas prácticas monumentales solo ocurren intramuros del cementerio, un espacio que en la geografía urbana española está relegado, como se ha mencionado, al exterior de las ciudades ${ }^{27}$. Además, la producción de estos monumentos no ha estado exenta de dificultades, trabas institucionales e incluso acciones violentas contra ellos. Se trata de iniciativas públicas, pero que fueron invisibles para el gran conjunto de la sociedad. Se les dio una escasa cobertura mediática, con excepciones como las del medio amarillista Interviú ${ }^{28}$. El monumento sobre las fosas comunes o erguido junto con los cuerpos exhumados se convirtió en un espacio no solo de duelo sino también de homenaje político. Partidos y sindicatos han acudido durante décadas a estos lugares el 14 de abril en la conmemoración de la proclamación de la República en 1931, el 1 de mayo, Día Internacional de los Trabajadores o el 18 de julio, aniversario del golpe de 1936, ante la ausencia de un lugar más adecuado en el centro del espacio público. Estos eventos se han producido siempre de manera abierta, el cementerio no deja de ser un lugar de libre acceso, municipal en la mayoría de los casos. Pero esa apertura no 
corresponde con lo que podría entenderse como espacio público en la tradición liberal del término : la plaza en tanto que espacio donde se representa y se describe ante la ciudadanía el estado, quien pertenece al mismo por su presencia en él, y quien no, por su exclusión ${ }^{29}$.

9 A la hora de realizar las exhumaciones durante los años setenta, existía una necesidad de que los cuerpos fuesen enterrados en el cementerio. A ello pueden asociarse dos grandes lecturas : por una parte, atiende a una necesidad de sepultura en base a la tradición cristiana ${ }^{30}$, pero por otra era retornarlos al espacio urbano como ciudadanos excluidos del mismo. Dada la falta de recursos científicos y de apoyo institucional, la excavación permitió la recuperación colectiva de los restos, pero no su identificación. Estas iniciativas tuvieron características propias en cada lugar, pero fueron siempre protagonizadas por familiares, militantes y allegados anónimos, quienes gestionaron por sí mismos la propia intervención. Generalmente autofinanciadas, se creaban comisiones gestoras y eventualmente lograron apoyo municipal ${ }^{31}$. Su exhumación, tenía un componente de ritual funerario. No habían sido enterrados adecuadamente, y el emplazamiento, fuera de la ciudad implicaba una humillación, que no solo se vinculaba así a la violenta distribución de los cuerpos. Bajo este patrón, en el marco de este tipo de acciones se encuentra como práctica habitual que tras la exhumación en regiones como Navarra y la Rioja, se transitase con los cuerpos por el centro las localidades concernidas por la exhumación. Jesús Aguirre ha recogido en su trabajo sobre la represión en La Rioja numerosas fotografías de las mismas ${ }^{32}$. Se puede ver en ellas a multitudes que sobrepasan el número al que podrían representar los simples familiares. Una de estas experiencias es la que en 1977 tuvo lugar en Cervera del Rio Alhama. Allí José Vidorreta, cuyo padre fue asesinado en 1936, gestionó la exhumación de su propio padre y sus compañeros, y organizó un evento de este tipo. Recorrieron las calles y pasaron frente a las casas de los asesinos con los cuerpos, al grito de "Viva la República" ${ }^{33}$. Sin embargo, en todos los casos, el destino final de los restos sería el cementerio. De nuevo un espacio de ostracismo para la urbanidad moderna, donde aún hoy se reúnen militantes y familiares los días de fusilamiento o en la festividad de los Santos. Y quizás conscientes de esa exclusión de la centralidad del espacio, desde hace 40 años se reúnen en cementerios estas particulares comunidades, tras una marcha desde el centro del espacio urbano. Un ejemplo de ello puede encontrarse en Dos Hermanas, provincia de Sevilla. Allí cada 18 de Julio, aniversario del fracasado golpe de estado, convocados por Pepe Sánchez, histórico militante local se produce una marcha desde el centro de la ciudad hasta la fosa común monumentalizada ${ }^{34}$. De esta manera estarían convirtiendo la propia peregrinación desde el centro de la ciudad en parte del ritual de duelo, pero a la vez uniéndose a una reivindicación que no claudica.

Este es un componente fundamental para entender la dimensión urbana de estas prácticas, especialmente dado que estas iniciativas no se produjeron solamente en los años setenta. Se han sostenido en el tiempo. De hecho, una de las iniciativas más grandes en este sentido tiene lugar desde 1997, en Valencia, última capital de la República Española. La comunidad militante local, disidente de las grandes formaciones de izquierda, comenzó a organizar actos de homenaje cada 14 de abril, día de la República. Cada año se concentran junto al río Turia, en el centro de Valencia, decenas de coches. Portan banderas republicanas, anarquistas, comunistas... y llegado el momento comienzan un recorrido por las calles de la ciudad, que vive ajena a su pasado. A través de una observación de la acción misma en 2019, era fácil reconocer, 
por una parte, el carácter festivo y de orgullo de los componentes de aquella caravana ${ }^{35}$. Es el día en el que tiñen la ciudad de sus colores y entre los edificios suenan los ecos de canciones republicanas. Pero, por otra parte, el ambiente contrasta con la perplejidad que reflejan los rostros de la mayor parte de los transeúntes. Para ellos el 14 de abril es un día más en el calendario. Pese a ello, resulta evidente que esta no es una ocupación del espacio cualquiera: como cada año tras dos horas de recorrido, se finaliza la caravana en la periferia de la ciudad. Precisamente en una encrucijada de carreteras donde lejos del núcleo urbano se ubica el cementerio de Paterna, donde más de 2.000 cuerpos fueron enterrados ${ }^{36}$. Allí la ruta termina con palabras de reivindicación, recuerdo y ofrendas florales ${ }^{37}$.

11 Y más marchas siguen surgiendo y he podido tomar parte en ellas y documentar otras en regiones como Castilla, Extremadura o Andalucía. El 18 de julio de 2019 se organizó por primera vez una marcha de este tipo en el Puerto de Santa María, Cádiz, en el aniversario del golpe y conectando el que fue centro de reclusión en el Puerto con la fosa común, ambos puntos ya monumentalizados ${ }^{38}$. La recurrencia de estas acciones revela una práctica discreta pero necesaria para estas comunidades de militantes y familiares : no solo haber hecho la fosa visible a través del monumento sino acudir a ella, desde el centro de la ciudad que les ha sido negado. Hacerse visibles, interrumpir el espacio vivido con su memoria traumática, comunicar la reivindicación y el dolor en el escenario de las calles. Y esto tiene una conexión no solamente con el pasado traumático, sino con el aspirar a que se haga justicia y que se dé una nueva presencia a la historia en la ciudad.

\section{Búsqueda de justicia y justicia espacial}

Xulio García Bilbao, miembro del Foro por la Memoria de Guadalajara me explicaba, a propósito de los eventos de homenaje que tenían lugar en el cementerio, que el 14 de abril, Día de la República, no acudían allí como hacían otras organizaciones políticas. Por el contrario, afirmaba que el 14 de abril ellos debían estar en el centro de la ciudad $^{39}$. Que precisamente la conmemoración y reivindicación del Día de la República sea condenada al cementerio como ocurre en muchos municipios donde existen fosas comunes monumentalizadas, habla de una falta de justicia espacial en base a la definición de Edward Soja. Este plantea como las acciones humanas tienen lugar en centros concretos. El hecho de que se trate de un espacio concreto inevitablemente condena a unos y a otros a disfrutar de ventajas y a sufrir desventajas, según su ubicación. De ello se traduce que la ciudad se haya convertido en un lugar privilegiado en el marco de las relaciones sociales y económicas actuales. La marginalización en la misma implicaría así restringir precisamente la participación en la vida social de la ciudad a un segmento concreto de la población, lo cual precisamente pone en conflicto tales acciones con las nociones de ciudadanía de pleno derecho, democracia representativa y justicia social ${ }^{40}$. Exactamente de esa situación se entendería que, ante la ausencia de participación en la vida social de la ciudad en el plano de la representación simbólica a través de memorias culturales tales como el monumento, se pida presencia en la misma. Y ésta no sería sino la demanda por una redistribución de los recursos sociales entre las cuales también se encontraría la espacialidad. Estaríamos hablando entonces de justicia territorial, en los términos de David Harvey ${ }^{41}$, la cual se 
encontraría implícita, aunque velada, en las demandas de justicia de los movimientos en torno a la Memoria Histórica.

13 Almudena Grandes en su recién publicado La herida perpetua señala a propósito de la Memoria Histórica, que antes de pasar página, hay que leerla ${ }^{42}$. Sin embargo, esta es aún una página del pasado por leer, y el modelo de monumento conmemorativo construido tras la Segunda Guerra Mundial incluso aparenta estar obsoleto. Los modelos en la Europa de hoy son superados a través de las propuestas del memorial o el contra monumento ${ }^{43}$. Pero son propuestas que aún no pueden llegar ya que no existen los propios monumentos a demócratas, luchadores antifascistas o víctimas del fascismo en los centros de las ciudades. Por el contrario, sobreviven avenidas y estatuas a los perpetradores ${ }^{44}$. El doble juego de dejar hacer activismo memorialista, sin llegar a promover una política de la memoria activa, marca la agenda política en muchas ocasiones si revisamos la mayor parte de las políticas de la memoria de las últimas décadas. Desinterés por judicializar el conflicto, y privatizar la memoria, como crítica abiertamente el Foro por la Memoria ${ }^{45}$. La producción social del espacio, siguiendo el concepto de Henri Lefebvre ${ }^{46}$, nos lleva a que no podamos percibir en él las violencias ni pasados traumáticos, pues se han concebido los monumentos desde el ostracismo y la marginalización en la ciudad. Esto solo se rompe los días que la comunidad decide activar sus peregrinajes hasta la evidencia del crimen : la fosa común.

La fosa común monumentalizada es la que ha permitido que no desaparezca por completo la presencia en el espacio público de estas memorias. Empero, al no ser que se pertenezca a la comunidad en la que se inscriben, estos lugares no han sido generalmente puestos en valor por las autoridades (con excepciones como la del Fossar de la Pedrera en Barcelona ${ }^{47}$ ). Pese a todo, la fosa común es un objeto del cual no se realizaban representaciones como tal. La fosa común resulta un patrimonio, una herencia, y cuando se fotografiaban las exhumaciones en los años setenta se producían imágenes testimoniales, se producían folletos, textos y fotografías ya que como señala Jimi Jiménez "estas familias, de alguna manera, fueron conscientes de que lo que estaban viviendo era algo especial, y que merecía ser recordado" ${ }^{48}$. Pero hubo muchas que nunca se localizaron, o en las que nadie se atrevió a intervenir. Así llegados los inicios del nuevo milenio, la fosa había sobrevivido en la memoria de una manera abstracta al mismo tiempo que la situación política cambiaba. El Partido Popular, heredero de la Alianza Popular fundada por Manuel Fraga, ministro de Franco, llegó al poder en 1996 y en el año 2000 obtuvo mayoría en el Congreso. Ante la crisis de valores de izquierda por parte del PSOE y del PCE en dicha situación, el pasado se convirtió en un arma electoral y la denuncia de los crímenes comenzó a ser incluida en los programas y propuestas parlamentarias ${ }^{49}$. El PSOE necesitaría en ese momento recuperar su imagen como partido de izquierda y progresista, sostiene Fernández de Mata, ya que tras una larga estadía en el gobierno marcada por el reformismo, moderantismo y revisionismo de sus principios socialistas habían llevado al partido no solo a perder el gobierno sino también su imagen socialista. De esta manera plantea Fernández de Mata, durante la segunda legislatura del Partido Popular, el PSOE invertiría en el capital simbólico de las víctimas para reconstruirse a través de una referencialidad al partido histórico y a sus votantes ${ }^{50}$.

15 Tras la llegada al gobierno del PSOE en 2004 entran en vigor una serie de medidas que respaldarían, al menos parcialmente, la posición que habían adoptado desde la oposición. Se crea ese mismo año, por decreto, la Comisión Interministerial para el 
Estudio de la Situación de las Víctimas de la Guerra Civil y del Franquismo y comenzarían a subsidiarse desde Presidencia del Gobierno actividades relacionadas con la denominada "Recuperación de la Memoria Histórica". Numerosas iniciativas comienzan a tener lugar y el año 2006 sería consagrado como "Año de la Memoria Histórica". Un año después se aprueba la "Ley 52/2007, de 26 de diciembre, por la que se reconocen y amplían derechos y se establecen medidas a favor de quienes padecieron persecución o violencia durante la Guerra civil y la Dictadura" conocida como Ley de la Memoria Histórica. En este sentido Aguilar observa cómo la Memoria Histórica pasó a ser desde el inicio de la legislatura, un eslogan, una bandera para la izquierda y los nacionalistas. Para ellos, la memoria era necesaria en tanto que suponía la recuperación de una tradición democrática a la cual ellos mismos se vinculaban ahora, mientras que si lo hubiesen hecho durante la transición podían haber sido tildados de revanchistas o nostálgicos ${ }^{51}$. Al mismo tiempo estas políticas de la memoria venían de la mano de una retórica de implicación a nivel internacional en el juicio a violaciones de los Derechos Humanos. Esto queda constatado cuando tras los enjuiciamientos contra las dictaduras chilena y argentina por parte del juez Baltasar Garzón, continúa con los crímenes imputables a la sublevación, Guerra y Dictadura española ${ }^{52}$. Pero para enlazar dicho debate público con las fosas comunes debe prestarse especial atención el hito mediático que supone la exhumación de una fosa común en El Bierzo en el año 2000. Para los medios esta exhumación inicia un nuevo proceso impulsado por los nietos y los movimientos de recuperación de la memoria histórica, que crearon asociaciones de memoria como la Asociación para la Recuperación de la Memoria Histórica (ARMH) ${ }^{53}$. Este tipo de organizaciones resultan de vital importancia en el proceso, pero a su vez iban a jugar un rol político fundamental, entendiendo que el apoyo a las exhumaciones podía ser un instrumento para la legitimación política en un momento de crisis de identidad del PSOE ${ }^{54}$.

16 La ARMH "central" monopolizaría por su parte muchos de los debates y actuaciones, viéndose favorecida por el marco legal impuesto por el PSOE para el fomento de un modelo privatizado de las exhumaciones de fosas comunes. Además, resulta fundamental comprender cómo basan su retórica en los Derechos Humanos, llegando a acudir al Comité para las Desapariciones Forzadas de Naciones Unidas, en lo que Francisco Ferrándiz ha denominado "el descubrimiento de las desapariciones forzadas en la España contemporánea" ${ }^{55}$. Y esto se manifiesta en otras formas, no artísticas, pero sí de intervención en el espacio público en el marco de sus protestas : la importación de la ronda de cada jueves organizada por las Madres de Plaza de Mayo fue incorporada por diversas organizaciones en esta misma línea de apelación a la justicia internacional de este nuevo juego discursivo, convirtiendo esa ocupación semanal del espacio público en un signo de identidad. Carla Pina describía así la actividad :

Buscan acabar con la impunidad de los crímenes cometidos durante la Guerra Civil y la posterior dictadura. Con ese objetivo se reúnen cada jueves, desde que inhabilitaron al juez Baltasar Garzón, en la madrileña Puerta del Sol, en lo que han llamado la Ronda de la Dignidad. Una plataforma que reúne a afectados directos del tardofranquismo y familiares de segunda o tercera generación, así como a asociaciones y diferentes grupos. Este día de la semana, llueva o nieve, rodean la estatua ecuestre de Carlos III y paran en cada vuelta frente a la fachada de la Real Casa de Correos, antigua sede de la Dirección General de Seguridad, recordando a las víctimas de torturas ${ }^{56}$.

17 Esta iniciativa, sin embargo, pese a ser altamente visible, no ha llegado a tener la fuerza que tenía el rondar en el contexto represivo de la Dictadura de la Junta Militar 
argentina. Aunque no deja de ser sintomática del estado actual de los procesos de justicia y las políticas de la memoria y su relación con el espacio público a la hora de representarse. Especialmente porque a la vez que surge esa iniciativa también comienza el uso de la propia imagen de la fosa en las manifestaciones. En varias ocasiones se ha podido ver en la misma Puerta del Sol, y utilizada por la misma organización una gran lona que reproducía a tamaño real la fosa de La Andaya, Burgos, con los cuerpos esqueléticos visibles ${ }^{57}$. Tanto es así que el asesinado ya no es representado en el núcleo del centro urbano a través de la puesta en escena política tradicional, donde se lo reivindicaba como un agente político, sino ahora como un cuerpo violentado a ser recuperado tras décadas enterrado en una fosa. De este modo, la negación de ese estatus de víctimas por parte de las instituciones sería un factor determinante en la constitución de la $\mathrm{ARMH}^{58} \mathrm{y}$ otras organizaciones en este momento, que pasan a reclamarlo. El dolor se convierte así en catalizador esencial para el activismo ${ }^{59}$. Pero la reivindicación de los asesinados como agentes políticos, tal y como se había hecho tradicionalmente desde el socialismo, el anarquismo y el comunismo, pierde su lugar en ese discurso. Estas personas, asesinadas décadas atrás pasan a ser solo considerados como víctimas y su recuperación corresponde al ámbito privado, y únicamente puede ser demandada por los familiares según recoge la Ley de Memoria Histórica de $2007^{60}$.

\section{La fosa hecha grafiti}

18 Es así como llegamos al proyecto de Alto en los muros de Tabacalera, centro social autogestionado en el corazón de Madrid, en 2014, y a lo que el arte urbano nos dice de los procesos de memoria en las últimas décadas. La imagen utiliza tonos apagados, como de fotografía echada a perder : colores beis, negro y blanco. En la franja superior del mural aparecen nueve cuerpos, con vestimentas que también asociamos a épocas pasadas : con faldas, chaquetas y sombreros. Por estas prendas deducimos su género. Mujeres, hombres, niñas y niños, entrelazados en abrazos y apoyados unos sobre otros. Sin embargo, algo perturba estos cuerpos. No tienen rostros. Alto los ha representado con manos y piernas. Es decir, vemos carne. Están erguidos, no son solo ropa. Pero no tienen rostros, como si fuesen invisibles en esa parte del cuerpo esencial para la individualización e identificación. Las ropas quedan vacías. Bajo ellos, en la franja inferior del mural, se amontonan huesos desordenados. Si contamos el número de calaveras, coinciden con el número de cuerpos sin rostro. Junto a ellas un enunciado "Contra la impunidad de los crímenes franquistas". Materializada la imagen, Alto la explicaba así para un medio online :

Pillé una foto real, de una familia de la guerra, y quería que se vieran dos cosas : la cantidad de gente enterrada sin que los reconozcamos y la reflexión de cómo hemos perdido la cabeza porque no queremos revisar el pasado. [...] Fue el punto de partida. Luego quise continuar, documentarme bien y ponerle número a cada fosa. Pretendía ser más riguroso con los datos, pero me di cuenta que lo importante era visibilizarlo. [...] Me había interesado desde hacía tiempo, aunque no tengo ningún familiar en esa situación. En cualquier caso, me siento identificado con los que atraviesan un problema así y, además, es nuestra historia ${ }^{61}$.

Las palabras del artista en relación a este proyecto nos hablan del potencial de ruptura de continuidad en el espacio vivido que puede suponer encontrarse con estas representaciones de fosas comunes que durante décadas han estado fuera del debate 
político. Visibilizarlas, pues pese a estar monumentalizadas en cientos de lugares, son desconocidas para la mayoría de la sociedad. No obstante, hay que entender que trasluce en este contexto la impronta del paradigma forense por encima del político. El propio artista reconoce su no vinculación familiar con asesinados en fosas comunes, de lo que asume que debe de haber una vinculación familiar para tener este tipo de motivaciones. Pero lo interesante es que no se refiere por tanto a una fosa concreta, aquella vinculada con la experiencia familiar o comunitaria, sino a fosas en abstracto. De hecho, la obra de Tabacalera es una de otras muchas representaciones de fosas que hizo en otros puntos de la geografía estatal como fosas que surgían de las esquinas, mostrando huesos y que eran numeradas de manera ficticia. Como si un número fuese la única manera de mentar esa acumulación de huesos.

Encontramos además en esta conversión de la fosa en "arte urbano", pese a que a veces el grafiti sea relegado a un segundo plano dentro del $\mathrm{mismo}^{62}$, que no se explicita la agencia política de las personas que fueron asesinadas. Y esto no deja de remitirnos precisamente a una despolitización que tiene su lugar en los movimientos que se han producido en torno a esta imagen. Los grafitis de Alto cristalizan así una realidad mucho más compleja a la de los crímenes de 80 años atrás. El discurso de los Derechos Humanos son el nuevo paradigma ${ }^{63}$, y ya no tanto en el de la reivindicación de los valores y causas políticas de las personas asesinadas. Lo inquietante de estas imágenes quizás sea que Alto no solo las despoja de los rostros, sino que nos muestra cuerpos que ya han sido despojados de su carne, pero hoy también se pretende desde ciertos sectores sociales dominantes, y desde la legislación, que también lo sean de su ideología y de la dimensión política por la que fueron asesinados. Manuela Bergerot, en relación a su colaboración con Alto, afirmaría "el movimiento memorialista necesita una nueva estética, un nuevo lenguaje que llegue a la ciudadanía, a generaciones más jóvenes" ${ }^{64}$. Pero, a pesar de esta afirmación no dudo que está llena de buenas voluntades, ¿es ésta una estrategia de representación un acercamiento a la sociedad en su conjunto ? ¿o por el contrario consecuencia de un leitmotiv?

\title{
Conclusiones
}

21 En relación al Street Art contestatario y reivindicativo en el Estado Español, Anne Puech afirma que

\begin{abstract}
En somme, ces interventions artistiques pourraient établir un rapport de force avec les institutions et peut-être parvenir, à plus long terme, à modifier l'ordre établi, mais seulement si elles s'inscrivent dans un plus large panel d'actions citoyennes et cohabitent avec les anciennes et les nouvelles modalités de la contestation, plus dynamiques et mobilisatrices. [...] Pour le moment, nous nous limiterons à constater que cette modalité a le mérite de témoigner du transfert de la démocratie dans une pratique quotidienne et de la capacité d'action de la société civile espagnole. Elle permet d'entretenir un esprit critique et de maintenir une forme de protestation et de résistance citoyenne ${ }^{65}$.
\end{abstract}

Este planteamiento no puede ser más revelador tras el breve, pero largo en el tiempo, recorrido desde los crímenes iniciados en 1936 hasta las fosas comunes pintadas por Alto en 2014. Precisamente cristaliza el hecho que señala Jesús Izquierdo a propósito de como el relato basado en la oclusión de unos y el ensalzamiento de otros, requeriría de "la promoción de políticas pluralistas de la memoria que desestabilicen, de una vez por todas, la narrativa porque nos construyó como los ciudadanos que por ahora somos" ${ }^{66}$. 
Alto clama contra la impunidad. Contra la impunidad es necesaria justicia. Para la justicia ha sido necesaria la acción familiar y militante durante décadas. Gracias a ellos se han conservado las fosas comunes en tanto que monumentos y desde ellas se han elaborado estrategias simbólicas para no olvidar el pasado. También habitando la ciudad en marchas y caravanas. Así, si bien es cierto que la supremacía de las imágenes de las exhumaciones y la retórica (únicamente retórica) de los Derechos Humanos han hecho invisibles otras muchas demandas, se pone de manifiesto la profunda injusticia. Injusticia no solamente por los crímenes no investigados, sino también la referente al espacio. El grafiti, si bien aporta una nueva estética y lenguaje más vinculado a los jóvenes, no dota de un lugar privilegiado al representado. Ocupa muros en desuso, como los de la Tabacalera en Madrid. Si bien se interrumpe el espacio vivido con sus imágenes, no dejamos de verlas como una consecuencia de la narrativa hegemónica de los sucesos en la actualidad.

En síntesis, querría concluir con la idea de cómo el estatus de víctima tiene mucho que ver con el de ser reconocido en tanto que ciudadano con derechos ${ }^{67}$ y precisamente el de ciudadano tiene que ver con el de ciudad ${ }^{68}$. Así, pasar de señalar la fosa en el ostracismo urbano a representarla en la calle en un espacio no privilegiado, después de décadas de marchas desde el centro urbano hasta las fosas comunes, resulta sintomático de esa situación. Los asesinados no son ciudadanos, están excluidos tanto fuera de la ciudad como fuera de las categorías jurídicas que los podrían llegar a considerar como víctimas. Tampoco su contribución, que podría ser recuperada en tanto que defensa de los valores cívicos republicanos ${ }^{69}$ es recuperada para honrarles simbólicamente a través del arte urbano. Así, si bien hacer la fosa visible tiene un papel mediático indudable a la hora de remover conciencias, conectar el centro de las ciudades, con las mismas, tiene un papel esencial en la construcción simbólica del espacio. Evitar que los cuerpos se pierdan no solo tendría una función judicial en la búsqueda de justicia en los marcos del estado, sino también la de crear una nueva percepción del espacio. Un espacio que aun deslegitima a los asesinados y no los pone en valor. Interrumpirlo con su representación surge en estas experiencias como un medio en la búsqueda de justicia y en la construcción de referentes, bien sea en el formato de monumentos, marchas o grafitis.

\section{NOTAS}

1. Paloma AGUILAR FERNÁNDEZ, “Aproximaciones teóricas y analíticas al concepto de memoria histórica : Breves reflexiones sobre la memoria histórica de la Guerra Civil Española (1936-1939)", Historia a debate: actas del Congreso Internacional Celebrado del 7 al 11 de julio de 1993 en Santiago de Compostela, vol 2, 1995, p. 129-142.

2. Disputed memories: Monumental practices on Spanish Civil War mass graves es un proyecto financiado en el marco del programa a.r.t.e.s. EUmanities, que ha recibido financiación del programa de investigación e innovación Horizonte 2020 de la Unión Europea en el marco del acuerdo de subvención Marie Skłodowska-Curie nº 713600. 
3. SUBTIERRO: Exhumaciones de fosas comunes y derechos humanos en perspectiva histórica, transnacional y comparada (Proyecto I+D+i CSO2015-66104-R) dirigido por Francisco Ferrándiz en el Instituto de Lengua, Literatura y Antropología - Consejo Superior de Investigaciones Científicas.

4. Astrid ERLL, Memory in culture, London, Palgrave Macmillan, 2011.

5. Maurice HALBWACHS, La mémoire collective, Gérard Namer (ed.), Paris, Albin Michel, 1997.

6. Aleida ASSMANN, Erinnerungsräume. Formen und Wandlungen des kulturellen Gedächtnisses, Munich,

C. H. Beck, 2018.

7. George DIDI-HUBERMAN, La imagen superviviente historia del arte y tiempo de los fantasmas según Aby Warburg, Madrid, Abada Editores, 2013, p. 34-35.

8. Ángel VIÑAS MARTÍN, "La internacionalización de la Guerra Civil de España", Anuario del Instituto de Estudios Zamoranos Florián de Ocampo, n³ 3, 1986, p. 615-631.

9. Paul PRESTON, The Spanish Civil War: Reaction, Revolution and Revenge, London, Harper Perennial, 2006, p. 102-34.

10. Francisco ESPINOSA et al., Morir, matar, sobrevivir : La violencia en la dictadura de Franco, Barcelona, Booket, 2004, p. 79-108.

11. Santos Julí́, Víctimas de la Guerra Civil, Madrid, Temas de Hoy, 1999.

12. Francisco ESPINOSA et al., Morir, matar, sobrevivir, Op. cit.

13. Francisco ESPINOSA, Violencia roja y azul: España, 1936-1950, Madrid, Crítica, 2010.

14. Paul PRESTON, The Spanish Holocaust, London, Harper Collins, 2008.

15. Miguel GonZÁLEz, "Defensa abrirá los archivos secretos de la Guerra Civil y el franquismo", El País, [on-line], (actualizado el 17/09/2018) [disponible el 08/09/2020], <URL : https://elpais.com/ politica/2018/09/16/actualidad/1537121723_032402.html>.

16. Francisco FERRÁNDIZ, "Fosas comunes, paisajes del terror", Revista de Dialectología y Tradiciones Populares 64 (1), 2009.

17. Thomas W. LAQUeUR, The Work of the Dead: A Cultural History of Mortal Remains, Princeton, Princeton University Press, 2018, p. 215-37.

18. Alfredo GRIMALDOS, Claves de la transición 1973-1986 : de la muerte de Carrero Blanco al referéndum de la OTAN, Barcelona, Península, 2013, p. 109.

19. Paloma AGUILAR, Políticas de la memoria y memorias de la política. El caso español en perspectiva comparada, Madrid, Alianza Editorial, 2008.

20. Paloma AGUILAR, "La evocación de la guerra y del Franquismo en la política, la cultura y la sociedad españolas", Santos Juliá (ed.), Memoria de la guerra y del franquismo, Taurus, 2006.

21. Zira Box, España Año Cero: La Construcción Simbólica Del Franquismo, Madrid, Alianza, 2010, p. 179.

22. Jesús de ANDRÉS SANZ, "Las estatuas de Franco, la memoria del franquismo y la transición política española", Historia y política : Ideas, procesos y movimientos sociales, no. 12, 2004, p. 161-186.

23. Giulia QUAGGIO, "1992 : La modernidad del pasado. El PSOE en busca de una idea regenerada de España”, Historia y Política, no. 35, 2016, p. 95-122.

24. Antonio BONET CORREA, "Espacios arquitectónicos para un nuevo orden", Arte del franquismo, Madrid, Cátedra, 1981, p. 11-46.

25. Elia CANOSA ZAMORA, Ángela GARCÍA CARBALLO, "Enmascarando la pobreza del paisaje urbano: rotondas y arte público”, Boletín de la Asociación de Geógrafos Españoles, no. 51, 2009, p. 249-273.

26. Zoé de KERANGAT, "Remover cielo y tierra. Las exhumaciones de víctimas del franquismo como fisuras del silencio en la transición", Tesis doctoral, Universidad Autónoma de Madrid, 2020.

27. Isabelle RENAUDET, "Du camposanto à la nécropole. Législation et pratiques funéraires en Espagne au XIX ${ }^{\mathrm{e}}$ siècle”, Bertrand Régis, Carol Anne (ed.), Aux origines des cimetières contemporains. Les réformes funéraires de l'Europe occidentale, XVIII ${ }^{e}-X I X^{e}$ siècle, Aix-en-Provence, Presses Universitaires de Provence, 2016, p. 275-297. 
28. Paloma AGUILAR, Francisco FERRÁNDIZ, “Memory, Media and Spectacle: Interviú's Portrayal of Civil War Exhumations in the Early Years of Spanish Democracy", Journal of Spanish Cultural Studies 17, no. 1, 2016, p. 1-25.

29. John PARKInSON, "Symbolic Representation in Public Space: Capital Cities, Presence and Memory", Representation 45, no. 1, 2009, p. 1-14.

30. Thomas W. Laqueur, The Work of the Dead: A Cultural History of Mortal Remains, Princeton, Princeton University Press, 2018, p. 312-335.

31. José Miguel GASTÓN, César LAYANA (eds.), Bajo tierra: exhumaciones en Navarra=Lur azpian: desobiratzeak Nafarroan, 1939-2019, Pamplon-Iruña, Nafarroako Gobernua-Gobierno de Navarra, 2019, p. 19-34.

32. Jesús Vicente AGUIRRE GONZÁLEZ, Aquí nunca pasó nada : La Rioja 1936, Logroño, Ochoa, 2012.

33. Entrevista el 21 de enero de 2019 en Cervera del Río Alhama con José Vidorreta.

34. Julio GUJjÁRRo GONZÁLEZ, “José Sánchez Gutiérrez. La Importancia de Recordar Todos Los Nombres" <URL : http://www.todoslosnombres.org/content/materiales/jose-sanchez-gutierrezla-importancia-recordar-todos-los-nombres>, [on-line], Todos Los Nombres. [disponible el 30/01/2020].

35. Plataforma 14 de Abril por la III República, "Caravana Republicana a Paterna", <URL : https:// es-es.facebook.com/events/alameda/caravana-republicana-a-paterna/428695911249004/>>, [online] Facebook [disponible el 30/01/2020].

36. Vicente A. GABARDA, "Un aspecte de la repressió franquista : els afusellaments a Paterna", Afers : fulls de recerca i pensament 2, no. 3, 1986, p. 261-270.

37. Cristian MORENO, "Caravana republicana y homenaje a los fusilados en Paterna". <URL : http:// www.unidadylucha.es $/$ index.php ?option =com_content\&view =article\&id =2275 :caravanarepublicana-y-homenaje-a-los-fusilados-en-paterna\&catid $=17 \&$ Itemid $=113>$, [on-line] Unidad $y$ Lucha (actualisé le 21/05/2017) [disponible el 30/01/2020].

38. C.B., "Marcha en recuerdo de las víctimas del franquismo por el 18 de Julio". <URL : https:// www.diariodecadiz.es/elpuerto/Marcha-recuerdo-victimas-franquismo-Julio-Memoria-

Historica_0_1373863042.html>, [on-line] El Diario de Cádiz (actualisé le 17/07/2019) [disponible el 30/01/2020].

39. Entrevista a Xulio García Bilbao en Guadalajara el 11 de enero de 2019.

40. Edward W. sojA, En busca de la justicia espacial, València, Tirant lo Blanch, 2014, p. 113-125.

41. David HARVEY, Social Justice and the City, Georgia, University of Georgia Press, 2010.

42. Almudena GRANDES, La herida perpetua, Tusquets, Barcelona, 2019.

43. James E. YounG, "The Counter-Monument: Memory against Itself in Germany Today", Critical Inquiry 18, no. 2, 1992, p. 267-296.

44. Jesús de ANDRÉS SANZ, "Las estatuas de Franco, la memoria del franquismo y la transición política española", Historia y política : Ideas, procesos y movimientos sociales, no. 12, 2004, p. 161-86.

45. Arturo PEINADO, "Las fosas del franquismo: qué y para qué", <URL: https:// www.cuartopoder.es/ideas/2020/02/12/las-fosas-del-franquismo-arturo-peinado>, [on-line] Cuartopoder (actualisé le 12/02/2020) [disponible el 12/02/2020].

46. Henri LefEBVRE, The Production of Space, Hoboken, Blackwell Publishing, 2016.

47. Ricard CONESA, "Del Duelo Clandestino al Recuerdo Colectivo : El Fossar de La Pedrera Del Cementerio de Montjuïc", Conxita Mir, Josep Gelonch (eds.), Duelo y Memoria : Espacios Para El Recuerdo de Las Víctimas de La Represión Franquista En Perspectiva Comparada. Espai/temps, no. 61, 2013, p. 171-198.

48. José Miguel GASTÓN, César LAYANA (eds.), Bajo tierra, Op. cit., p. 26.

49. Paloma AGUiLAR, "La evocación de la guerra y del Franquismo en la política, la cultura y la sociedad españolas", Santos Juliá, Memoria de la guerra y del franquismo, Madrid, Taurus, 2006. 
50. Ignacio FERNÁNDEZ DE MATA, “El surgimiento de la memoria histórica. Sentidos, malentendidos y disputas", Luis Díaz, Pedro Tomé (eds.), La tradición como reclamo : antropología en Castilla y León, Valladolid, Junta de Castilla y León, 2007, p. 195-208.

51. Paloma AGUILAR, "Las políticas de la memoria”, Ana Bosco, Ignacio Sánchez-Cuenca (eds.), La España de Zapatero. Años de cambios, 2004-2008, Madrid, Editorial Pablo Iglesias, 2009.

52. Sophie BABY, “¿Latinoamérica : un desvío necesario ? Baltasar Garzón, de Pinochet a Franco”, Amnis, [on-line] 2, 2011. <URL: https://journals.openedition.org/amnis/1485>, [disponible el 10/09/2020].

53. ARMH, “¿Quiénes somos?”, <URL: https://memoriahistorica.org.es/que-es-la-asociacionpara-la-recuperacion-de-la-memoria-historica-armh-2000-2012>, [on-line] ARMH [disponible el 12/02/2020].

54. Daniel PALACIOS GONZÁLEZ, Miriam SAQQA CARAZO, "De la exhumación a la monumentalización : Una perspectiva interdisciplinar sobre la legitimación política en España desde el año 2000", Amnis, [on-line] 18, 2019. <URL : https://journals.openedition.org/amnis/4377>, [disponible el 10/09/2020].

55. Francisco FERRÁNDIZ MARTíN, "De las fosas comunes a los derechos humanos : el descubrimiento de las 'desapariciones forzadas' en la España contemporánea”, Revista de antropología social, n 19, 2010, p. 161-189.

56. Carla PINA, "Rodear la Puerta del Sol para no olvidar", <URL : https://ctxt.es/es/20160720/ Politica/7369/ronda-dignidad-franquismo-victimas-puerta-sol.html>, [on-line] ctxt (actualisé le 26/07/2016) [disponible le 12/02/2020].

57. Natalia JUNQUERA, “Una 'fosa común' con 29 cadáveres en la Puerta del Sol”, <URL : https:// elpais.com/diario/2010/09/03/espana/1283464813_850215.html>, [on-line] El País (actualisé le 03/09/2010) [disponible le 12/02/2020].

58. Ignacio FERNÁNDEZ DE MATA, "El surgimiento de la memoria histórica", Art. cit.

59. Gail holst-WARhaft, The Cue for Passion: Grief and Its Political Uses, Harvard University Press, Cambridge, 2000.

60. Ley 52/2007, de 26 de diciembre, por la que se reconocen y amplían derechos y se establecen medidas en favor de quienes padecieron persecución o violencia durante la Guerra civil y la Dictadura. "BOE" n 310, 27 de diciembre de 2007.

61. Alberto G. PALOMO, "El grafitero que pinta la memoria histórica ahí donde está", <URL : https://www.yorokobu.es/grafitis-alto-fosas-comunes/ >, [on-line] YOROKOBU (actualisé le 19/12/2017) [disponible le 12/02/2020].

62. Anne PUECH, Street Art Contestataire et Revendicatif En Espagne : Formes et Pouvoir d'un Engagement Esthétique, Social et Politique, Thèse de doctorat, Université Angers, 2014, p. 56.

63. Francisco FERRÁNDIZ MARTín, "De las fosas comunes a los derechos humanos : el descubrimiento de las 'desapariciones forzadas' en la España contemporánea”, Revista de antropología social, no. 19, 2010, p. 161-189.

64. Manuela BERGEROT, “Arte Urbano con Memoria", <URL: http:// www.margenesdelamemoria.org/2014/12/10/arte-urbano-con-memoria/ >, [on-line], Márgenes de la Memoria (actualizado el 10/12/2014) [disponible el 12/02/2020].

65. Anne PUECH, "Street Art contestataire et revendicatif dans l'Espagne du début du xxie siècle : formes et pouvoir d'un engagement esthétique, social et politique", Cahiers de civilisation espagnole contemporaine. De 1808 au temps présent, [on-line], 15 | 2015, URL : http://journals.openedition.org/ ccec/6033>, (actualizado el 14/01/2016) [disponible el 10/09/2020]. 14 janvier 2016, consulté le 10 septembre 2020 .

66. Jesús IZQUIERDO MARTíN, “¿Víctimas sin victimismo? Por una memoria elaborada del genocidio franquista”, Gabriel Gatti (ed.), Un mundo de víctimas, Barcelona, Anthropos, 2017, p. 165-182. 
67. Gabriel GATTI, María MARTíNEZ, "El campo de las víctimas. Disensos, consensos e imaginarios compartidos con el nacimiento del ciudadano-víctima", Gabriel Gatti (ed.), Un mundo de víctimas, Barcelona, Anthropos, 2017, p. 73-90.

68. Carlos MAgino Rodríguez, "La concepción de la ciudad, de la ciudadanía y del ciudadano en Aristóteles", Bajo palabra. Revista de filosofía 2, n 7, 2012, p. 219-235.

69. Oscar PÉREZ DE LA FUENTE, "Sobre las virtudes cívicas : el lenguaje moral del republicanismo", Derechos y libertades : Revista del Instituto Bartolomé de las Casas 14, n² 23, 2010, p. 145-181.

\section{RESÚMENES}

Las fosas comunes son uno de los legados más controvertidos del golpe de estado de 1936 y de la posterior guerra y dictadura en España. Son la consecuencia de un plan de genocidio planificado y el debate se ha monopolizado en torno a la supuesta Memoria Histórica. Propongo confrontar los debates actuales sobre justicia y representación con diferentes manifestaciones de la memoria cultural. Los monumentos, las marchas y los grafitis permiten reconocer una deriva desde la simple señalización de las fosas comunes hasta la insatisfacción por la falta de justicia. Una falta de justicia que no sólo se limita a los crímenes de la Guerra y la Dictadura. También existe un vínculo con la espacialidad. Las estrategias para la preservación de las fosas comunes son similares a las de la visibilidad en el espacio público. Debido a sus características, las fosas comunes se encuentran en las afueras de la ciudad. Por lo tanto, la exclusión de los asesinados de su sociedad refleja la exclusión de su representación en el espacio público. Las estrategias más recientes, ilustradas por un caso concreto de graffiti en las fosas comunes, cristalizan el estado de las demandas de justicia y las posibilidades de representación en el espacio público de quienes fueron asesinados hace 80 años.

Les fosses communes sont l'un des héritages les plus controversés du Coup d'État de 1936, de la Guerre et de la Dictature qui s'ensuivirent en Espagne. Elles sont la conséquence d'un programme de génocide planifié et le débat a été réduit à ce que l'on nomme la Mémoire Historique. Je propose de confronter les débats actuels sur la justice et la représentation avec différentes manifestations des mémoires culturelles. Les monuments, les marches et les graffitis permettent de reconnaître une évolution de la simple signalisation des fosses communes au mécontentement dû à l'absence de justice. Un manque de justice qui ne se limite pas seulement aux crimes de la Guerre et de la Dictature. Il existe aussi un lien avec l'espace. Les stratégies de préservation des fosses communes rejoignent celles de la visibilité dans l'espace publique. En raison de leurs caractéristiques, les fosses communes se trouvent à la périphérie de la ville. Par conséquent, l'exclusion des personnes assassinées de leur société reflète l'exclusion de leur représentation dans l'espace public. Les stratégies plus récentes, illustrées par un cas spécifique de graffitis sur des fosses communes, cristallisent le statut des demandes de justice et les possibilités de représentation dans l'espace public de ceux qui ont été assassinés il y a 80 ans.

The mass graves are one of the most controversial legacies of the 1936 coup d'état, and consecuent war and dictatorship. These are the consequence of a planned genocide plan and even today, they are a complex heritage. The debate has been monopolized around the field of so-called Historical Memory. I propose to confront the current debates on justice and representation with various manifestations of cultural memories. Monuments, rallies and graffiti 
make possible to recognize a drift from the simple marking of the mass graves to the discontent on the lack of justice. A lack of justice that is not only limited to the crimes of the war and the dictatorship. This is also link with spatiality. The strategies to preserve the graves join those to get visibility in the urban space. Because of their features, the graves are on the outskirts of the city. Consequently, the exclusion of the murdered from their society reflects the exclusion of their representation from the public space. The most recent strategies, illustrated in a specific case of graffiti on mass graves, crystallize the status of the demands for justice and the possibilities of representation in public space of those murdered 80 years ago.

\section{ÍNDICE}

Mots-clés: mémoire, art urbain, patrimoine, guerre, histoire, justice

Palabras claves: memoria, arte urbano, patrimonio, guerra, historia, justicia

Keywords: memory, urban art, Heritage, war, history, justice

\section{AUTOR}

\section{DANIEL PALACIOS GONZÁLEZ}

(Universität zu Köln y Universidad Autónoma de Madrid) 